\title{
Presence, Routines, and Technology Discrepancy - Information Exchange between Parents and Preschool Teachers
}

\author{
Stina Nylander \\ Swedish Institute of Computer Science, Box 1263, 16429 Kista, Sweden \\ stny@sics.se
}

\begin{abstract}
We have interviewed four parents and a teacher at a Swedish preschool to investigate the practices for spreading information in preschool. Our findings suggest that frequent presence in the premises of the preschool is important to get information, and that parents rely heavily on routines to make it work. When either of these points fail, breakdowns occur. Discrepancies in parents' and teachers' IT use also complicates the information exchange.
\end{abstract}

\section{Introduction}

Family life and the elements of planning, coordination, and problem solving it encompasses have received a lot of attention in the HCI community in the recent years. Various studies have shed light on families organize their lives using various tools such as paper lists [11], home made organizing systems [10], and paper calendars [1], how they communicate and coordinate their information [3], and how this work could be supported by smart home systems [2]. This research has focused on the family as a unit and explored how family members communicate with each other, organize incoming information, and negotiate their everyday tasks. We add to this body of knowledge by looking at the information exchange between the family and an external unit, preschool. Families stay in contact with many external units such as schools, sports teams, authorities, doctors and the like. We have chosen preschool since it is a daily activity, involves different types of information in both directions, and breakdowns can have potentially cumbersome consequences such as a parent having to stay home from work unexpectedly.

The information exchange between parents and preschool teachers is frequent and important. Parents get a lot of practical information and information about their children's development from preschool teachers. They also need to convey information about the children to the teachers. A large part of the information exchange takes place in the premises of preschool where parents talk to teachers, pick up paper notes, reads notes posted on notice boards etc. Some information is conveyed over the phone while email is used very little in the studied preschool. Parents then bring the information home and incorporate it in their own organizing system to keep track of what is going on.

We have investigated the practices for information exchange between teachers and parents at a Swedish preschool through interviews with four parents of preschool 
children, and a preschool teacher. Here we focus on the present handling of written information. Our findings suggest that the existing routines for keeping track of information rely heavily on presence (at home and in preschool) and that the information usually is non-portable. We also noted a discrepancy between the parents' and the teachers' use of information technology that seemed to influence the information exchange. We conclude the paper by presenting some implications for future design of information technology for family use.

\section{The Studied Preschool}

In Sweden, $80 \%$ of children aged 1-5 attended preschool in 2007. At the age of six, they start in "preschool class" which is a preparatory year between preschool and school. In average, children are 18 months old when they start preschool.

Two main professional groups work in preschool, preschool teachers and child care assistants. The preschool teachers have 3.5 years of university education in pedagogy, and children's development and learning, combined with a variety of specializations such as music, drama, science for children etc. The child care assistant education is given within high school. Formally, preschool teachers have the pedagogic responsibility while the child care assistants are in charge of the practical issues of taking care of children. In this paper, we will refer to both groups as teachers.

Parents pay a fee for their children to go to preschool. The fee is $3 \%$ of the parent's income with a ceiling of $1260 \mathrm{SEK} /$ month for 2008. If a family has more than one child in preschool the fee for the second and third child is reduced. Children aged 4 and 5 have a right to 15 hours a week of preschool without charge. In Sweden, there are public preschools, private preschools and preschools run by parents, but they all operate with the same fees.

When it comes to technology and its use, the differences between various preschools are huge. The migration from paper to digital information in the administration work is basically completed by now, but many preschools have old computers, extremely slow Internet connections, no digital cameras or other technology. The differences are also large in how the existing technology is used in the pedagogic work with the children. Some preschools use digital cameras and camcorders to document the activities and let children watch and manipulate the pictures using the computers. Drawing software and games are also used with the children. The use of technology with the children of course depend on what kind of technology the preschool have access to, but also how comfortable teachers are with using it.

Here we do not focus on the specific organization of preschools or how the pedagogic activities are carried out, but exclusively on the information exchange between teachers and parents that are necessary to make everything work. The daily communication between parents and teachers about a child and the activities of the day, as well as the information about events, things to bring, meetings and other issues are present in all kinds of child care in many cultures. We therefore believe that the issues that we discuss in this paper are not only relevant for the case of Swedish preschools but also for a larger cultural context.

The preschool that was the target of this study takes care of 37 children divided into two groups, 16 children in a younger group (1-2 years old) and 21 children in an 
older group (3-5 years old). The younger group is attended to by three teachers, the older group has four teachers.

The preschool is equipped with computers and Internet access that are used for both administrative tasks and pedagogic activities with the children. Teachers use the computers for example to write notes and letters to parents, report their working hours, and to show parents pictures and movies of what the children are doing in preschool. The children use the computers for example for drawing, watching digital pictures that they have taken themselves (or the teachers have taken of them), and watching movies that the teachers take of certain activities in the preschool. Email is used within the organization for communication between teachers at different preschools, organization of teachers' conferences and spreading of administrative information. It is only used tentatively for communication between parents and teachers.

\section{Related Work}

Research from the past few years has shown that family life demands a great deal of effort to manage and coordinate [3]. Families need to keep track of information from various sources about events, responsibilities, people, and things. Paper calendars displayed in the kitchen or other central places in the home are common tools to help families $[1,7]$. Taylor \& Swan have also described how this is done using paper lists [11] and other home made organizing systems such as charts or notebooks [10] to achieve the flexibility needed in combination with the beauty, personalization, and functionality desired. The above approaches have in common that they have focused on the family and how they manage incoming information and keep track of it. Little attention has been given to the sources of the incoming information or to how the family informs others about itself. We would like to add to the body of knowledge on family coordination by studying how the family communicates with an external unit and how that information exchange works. Here, we have chosen preschool as the external unit.

Many attempts have been done to design and implement various applications that would support families with the wall calendar as the most frequently used application. The attempts bear witness of the difficulties to replace well established domestic routines based on traditional tools such as notice boards and paper calendars with information technology. Crabtree et al. [1] points out that it is not a good idea to replace a paper wall calendar with individual electronic calendars since the wall calendar has an important purpose of serving as a central point of information and awareness. Neustadter et al. show in their trials with the LINC prototype digital wall calendar that it is not trivial to replicate the flexibility and the ease of use of the paper calendar even though they have taken important steps in the process [7,8].

Another body of work that is relevant for this work is the smart home domain. Davidoff et al. [2] have investigated how a smart home could support families to manage information. Another example is the smart bag [5] where an object is augmented with sensor technology to be able to help its owner remember what to pack and to bring the bag to the right event. In the particular case presented here we do not advocate anything like a smart home infrastructure but we definitely acknowledge the possibilities of information technology to be of help in family organization. Our case of preschool 
teachers and parents call for simple, robust and easy to use solutions, which leads us to envision trials with email and text messages, technologies already well integrated in participants' lives.

\section{Method}

The routines for information exchange between parents and preschool teachers have been examined through interviews. Four parents and one preschool teacher have been interviewed individually. The interviews lasted 45-60 minutes and were recorded. Three of the parents were interviewed at home while the fourth interview was conducted in a quiet restaurant. One or two children were present during the interviews that were conducted at home. The teacher was interviewed in the premises of the preschool. The parents were recruited at a parent-teacher meeting at the preschool that the author attended. The interviews focused on the routines of the preschool for giving information to the parents, how parents give information to the teachers, how the parents keep track of all the information, and where the breakdowns occur. A few questions were also asked about the parents' experience with technology such as the Internet, email, and cell phones.

We are aware of the drawbacks of self-reporting as a method of gathering data, especially in a case such as ours that is surrounded with strong social norms. However, we believe that parents have been honest enough. One of our participants reported having forgotten to pick up a child in time and received a phone reminder from preschool, and others reported several cases of forgotten stuff that should have been brought and other mistakes. In addition, the stories of the interviewed parents matched the story of the interviewed teacher well.

The interviews were complemented with a visit to the preschool where pictures of places and artifacts relevant to the information spreading process were taken.

\subsection{Participants}

Participant 1 (P1) was a married woman in her thirties with two children, one and three years old. At the time of the interview, she was on maternity leave with her youngest child, but her older child still attended preschool a few days a week. Since she was staying at home she took care of the dropping off and picking up at preschool, and also kept track of all information concerning preschool. Her primary tool for that was a day planner where she noted all important information. She reported that she used the Web and email frequently during her maternity leave, and would go back to her work where she uses the Web and email daily. Her cell phone was Web enabled and she had tried to surf from it once.

Participant 2 (P2) was a married woman in her thirties with one four year old child. Both she and her husband were working, and she took care of most of the dropping off and picking up their child at preschool, with some help from her mother-in-law that sometimes picked her child up from preschool. She was the one in the family that is responsible for keeping track of the information from preschool, and wrote things down in a day planner that she carried in her purse. The list of dates when the preschool is closing early was posted on the fridge, and she sometimes let notes from 
preschool lie visible in the kitchen so that her mother-in-law could read them. She used email daily in her work and had a Web enabled cell phone. She had tried occasionally to surf from the phone but it was not a habit.

Participant 3 (P3) was a married man in his forties with six children, three with his current wife (aged two, four, and six), and three teenagers from a previous marriage of which two lived every other week with his current family. The two youngest children attended the preschool described in this study. Both he and his wife worked, and they shared the responsibility of dropping off and picking up children. The family had a kitchen calendar with one column for each person in the family where important events and reminders were noted, which he referred to as the main information point in the house. He kept his own calendar in his cell phone, his wife had her calendar, and he reported that their personal calendars usually were not fully synchronized with each other. Besides the kitchen calendar the family also had a poster by the front door with things that needed to be remembered for each day of the week, such as sports clothes Monday, picnic lunch Tuesday etc. He used email daily both for work and private purposes (but used different computers for each purpose to keep them separated), and had a Web enabled cell phone but did not use it to surf the Web.

Participant $4(\mathrm{P} 4)$ was a married woman in her forties with two children aged four and six, of which the youngest attend the preschool described here. Both she and her husband were working, and they shared the responsibility of dropping their children off and picking them up at preschool. Her husband dropped them off every morning, she picked them up three days a week, and the other two days the grandmothers picked them up one day each. She was the one responsible for keeping track of the information in the family and writing it down in the kitchen calendar or posting it on the message board. Usually, she also told her husband when something was going on since he rarely looked in the calendar. She had no personal day planner. She had a desk calendar at work where she also noted personal and family events. In her work she used email daily but she had never tried to surf from her phone.

\section{Different Types of Information}

The main information channels between parents and teachers are paper notes (mostly from teachers to parents) and face-to-face communication. Paper is used for information about dates, events, decisions and reminders. A monthly information letter with summaries of the past month's activities and important dates to come is distributed to the parents, complemented by reminder notes and extra notes when something comes up. Email is only used occasionally in the studied preschool. No routines have been established yet as to what information could be distributed electronically. The information exchanged between parents and teachers mainly concern three broad areas:

- the children and the activities in general - parents tell teachers in the morning if there is anything special with their children that day, teachers tell parents in the afternoon what has happened during the day. The main part of this information exchange is oral, but teachers usually write a summary of the day's activities in the school's wall calendar.

- logistics - parents inform teachers about when the children will be picked up, sick children that are not coming to school, doctor's appointments, vacation dates 
and the like using face to face conversations, phone calls and paper notes. Teachers inform parents about things to bring, when preschool is closing early, diseases etc. using face to face conversations and paper notes.

- $\quad$ events - the preschool is taking the children to the theatre, parents are invited for the Easter party etc. This information is always conveyed in written form, in the monthly letter, separate notes or both.

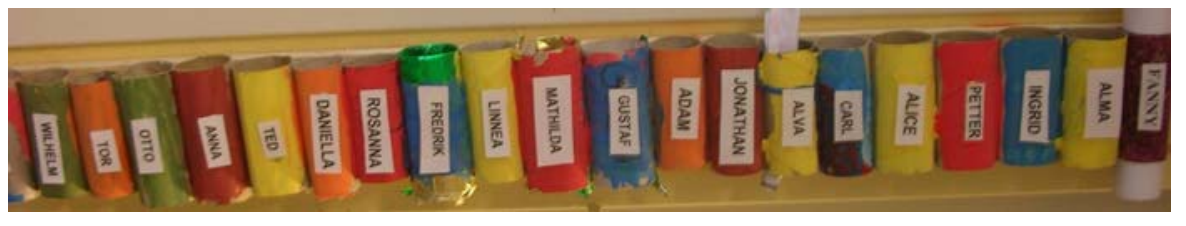

Fig. 1. The toilet paper rolls that are used as mail boxes

\section{Strategies to Make Information Exchange Work}

Parents have tricks and strategies to keep track of information as well as teachers have strategies to make parents pay attention. Some strategies are used by both parents and teachers.

\subsection{Strategy 1: Display Information in Prominent Places}

Both teachers and parents display paper notes in prominent places to disseminate and remember important information. This strategy works well as long as the concerned persons frequent the places where the information is displayed.

The most important source of information for the parents is a toilet paper roll (see figure 1). Each child has paper roll attached to the wall besides the entrance which serves as a mail box. All the written information from the teachers is put in the roll. The interviewed parents reported that the first thing that they did when entering the preschool was to check if there was anything in their child's roll.

There are several message boards in use. At the entrance there is one with general information to parents, such as the pedagogic plan, documentation from PTA meetings, important phone numbers, the menu for the week etc. Each of the two child groups also has a message board where information about the daily activities is posted. Important information is posted on the front door so that no one can leave the building without noticing. Especially important information is also posted on the outside of the front door so that it is visible on arrival, for example the reminder that the preschool is closing early today.

Prominent places are also used to display information in the home. A wall calendar in the kitchen is a common way to organize information concerning various family members $[1,7]$. Three of the interviewees reported that their family had one where everything was written down. One of them usually looked at the calendar in the evening, after dinner, another one looked at least every morning.

"I look at the calendar several times a day. Don't know why, guess I'm afraid to forget something." (P4) 
Several participants also reported having other places for information in the kitchen in addition to the wall calendar, such as a notice board or notes posted on the fridge. This lies well in line with the findings of [3] that information tend to gather in the places where all the family gathers.

One family had a poster on the inside of the front door with a list of things that needed to be remembered or packed for each day of the week: fruit on Monday, sports clothes on Tuesday, picnic lunch on Wednesday etc. However, such a reminder easily gets ignored after a while:

"Maybe we should move the poster around once in a while so that we notice it. Now we almost don't see it anymore." ( $\mathrm{P} 3)$

Remote access to some of the information concerning preschool could help teachers to disseminate information and parent to keep track of it. This will be further discussed in the section on Design Implications.

\subsection{Strategy 2: Establish Routines}

Routines are important tools for making the family-preschool puzzle work [12], and our participants relied on them for various related tasks. Many of the reported breakdowns related to deviations from routines.

All the interviewed families had their own fixed schedule for who was dropping off and picking up the children from preschool to avoid misunderstandings.

"My husband drops the kids off every morning, I pick them up three days and each grandmother picks them up one day." (P4)

Three of the interviewees said that their family had an explicit agreement that the person picking up the children also brings home any note that is found in the roll. Taking the note in the morning had proved to be a bad strategy.

"I don't dare to take it in the morning, I did it once and it got lost and we missed something. It's better to take it directly home and write down the info in the wall calendar" (P3)

However, there are often deviations from routines [2]. The most frequently mentioned example in the interviews was the monthly early closing of the preschool. This means that all children need to be picked up at $3.45 \mathrm{pm}$ at the latest, compared to $6 \mathrm{pm}$. These dates are announced in a special note that is distributed in the beginning of the semester, it is mentioned in the monthly letter and it is posted on the front door on the actual day. Parents reported carefully noting these dates since they need to depart from their established routine of picking up their children. However, staff reported that in average one family per occasion (different families every time) was late to pick up their children the day when they close early, and needed a reminder by phone. A probable reason for this is of course that deviations from routines are always difficult, especially when they occur as seldom as once a month. However, it is very common that one parent drops the kids off and the other parent picks them up which breaks the principle of presence. The parent that sees the reminder in the morning is not the one that needs to come early in the afternoon. For some families, nannies and/or grandparents are also involved in picking children up from day care. Moreover, the usual 
case is that the parent picking up the children comes directly from work which means that they do not have access to the family's central kitchen calendar. Our findings suggest that the present methods for spreading information in the preschool in question do not fully handle deviations from established routines. These situations call for information adapted to the situation such as various kinds of contextual reminders which will be further discussed in the section on Design Implications.

\subsection{Strategy 3: Use Information Technology}

Our participants reported using information technology such as email and the Web daily both for work and private purposes. Two participants reported using mobile technology to help them manage their personal information. One of our participants reported that he, for personal purposes, used his cell phone as a calendar and that he frequently used the alarm function to be reminded about upcoming calendar events.

"An hour before you came the phone beeped and reminded me that you were coming, otherwise I would have forgotten completely." (P3)

Another participant reported that she did not use the calendar functionality in her cell phone but that she frequently used "mobile notes". With mobile notes she could make a note about an upcoming event and put it as a wall paper on the screen of the cell phone. Since she used the phone instead of a watch she looked at it repeatedly during the day and thus saw the reminder for the event.

\section{"That way it is rubbed in." (P4)}

The preschool, though, used very little electronic information in their communication with the parents. A few short-lived attempts with email reminders for the days when the preschool closes early had been made but no routines were established. All interviewed parents reported using email and the Web daily, and two of them reported that they would like the preschool to use email for certain information purposes.

\subsection{Fallback Strategies, When All Else Fail...}

Of course, even though strategies for disseminating information may be carefully designed and well implemented, they sometimes do fail. One example that came up during the study was the collection of vacation dates for all families before the summer (the study was conducted in late May so the topic of vacation was highly relevant). Forms for reporting the vacation dates had been distributed to the parents during April and posters to remind them to hand the forms in had been posted in the premises. However, many parents did not return the forms so teachers fell back to good old "chasing and reminding". They tried to keep in mind who had returned the form and reminded those who had not. This sometimes took the form of going to the office to check who needed to be reminded and, during that time the family had left so the teacher had to run after them out on the side walk. The interviewed preschool teacher reported that such things take a lot of time. Teachers also remind parents in more general situations such as when there is an event scheduled for tomorrow. One of our interviewed parents said that he did not know if teachers reminded everyone or just him about events, but he did not mind being reminded. 
"It doesn't bother me [to be reminded about events or things to bring]. It would be worse if they said 'don't forget to pick up your kid', that would hurt more.” (P3)

Participants also reported that they sometimes call other parents, or the preschool, to find out if something special is up, for example if they have been away for a few days.

"If the kids have been sick we usually call preschool to check if something is up for next week. If we have been away we check with other parents if there is something we need to know." (P3)

\section{Breakdowns and Consequences}

Breakdowns usually happen when deviations from routines occur, such as when the preschool closes early, or during periods of time when parents have a lot on their mind such as the weeks before Christmas. Consequences are mostly minor, (often due to the flexibility of the teachers) but none the less they cause irritation, frustration, and restrict the teachers' time with the children.

The most serious consequences of information breakdowns are those who steal time from the main tasks that teachers are to perform. For example, when parents do not provide requested information in time (such as vacation dates), teachers need to spend a lot of time keeping track of who has not provided the information and remind them in various ways. One such problem used to be parents that needed phone numbers to other parents because the children set up play dates themselves during the day. Thus, in the afternoon when many parents arrive at the same time and want to talk to the teachers about the day, they have to go into the office to get phone numbers. This was so frequent and time consuming that it was solved by posting a list with names and phone numbers at the entrance so parents can find the numbers without asking the teachers. The interviewed teacher reported that it is very important for all teachers to be able to spend time with the children. That is their main work task and also the most rewarding one. When the time with the children is restricted due to administrative work, extra information work or other tasks, teachers easily get frustrated and feel that they are not allowed to do their job. Therefore, they work hard to make the information exchange with parents as efficient as possible.

"When the time with the children shrinks the teachers get frustrated." (Teacher)

An example that came up over and over again in the interviews was the issue of preschool closing early one day a month to allow the teachers to plan their work. When parents are late it creates problems for the teachers since they do not leave children unattended. In these situations someone misses the planning session since they must take care of the child/ren that are not picked up in time. It was also described as an awkward situation since teachers did not feel that they could call parents and remind them until about $4 \mathrm{pm}$. If the parents then were still at work it would often take them more than 30 minutes to arrive to preschool.

"Sometimes you don't want to call because it gets embarrassing. You call them after 15 minutes and they are still down town." (Teacher) 
Parents mostly reported bad conscience and feelings of being a bad parent as consequences of information breakdowns.

\section{"You do want to do things right.” (P1)}

Practical problems could usually be solved by quick expeditions back home to get things that were left behind or to the grocery store when the picnic lunch was forgotten.

\section{"Luckily, Engströms [the nearest grocery store] opens at 8am." (P2)}

Parents also reported that the preschool teachers work hard to keep the consequences from the children when breakdowns occur. For example, the children of course get lunch even if the parents have forgot to report that they are not sick anymore and will be back at preschool, and children do not get left behind when the preschool is closing early and parents forget about that. However, the interviewed parents reported that such breakdowns sometimes cause family internal arguments.

"We argue about whose fault it was." (P3)

\section{Implications for Design}

Our findings suggest that many issues of parent-teacher information exchange center around three areas: presence, deviation from routines and discrepancies in technology use. Below we will discuss their implication for future design of technology for preschool use.

\subsection{Presence, Absence, and Remote Access to Information}

The routines of spreading necessary information both to parents and to teachers rely heavily on physical presence in the facilities [9]. In many cases this works well since parents drop off and pick up their children every day, which allow them to both get information from and give information to the teachers. However, if a child is absent due to illness there is a problem. Very little information gets through if you are not coming to the school.

"Before Christmas last year we were sick a lot and we totally lost track of what was going on. I think we missed a lot that we didn't even know about." (P1)

The interviewed parents reported that they sometimes call the preschool or other parents to check if something has come up while they have been at home with sick children.

The other central place for information is the home. Most of the interviewed families had a wall calendar in the kitchen and a message board for notes. This information is accessible even when children are staying at home sick, but when the family is traveling or the parents go to work they lose access to the information. Picking up children in the afternoon is for example an activity that does not start from home. Parents go from work to the preschool to pick the children up which means that they cannot check the kitchen calendar during the day to see if there is something special to adapt to. Even though home and preschool are natural places for storing information they are not the only places where parents need information access. There is a 
workplace for each parent, homes and workplaces for potential other persons involved in the child care, and transit places such as subway trains and cars. Some of the children also have divorced parents and thus two "homes", many of them spending every other week at each home. Access to preschool information from other places than the home and the preschool could obviously be beneficial. Remote access to the information would also reduce problems that occur when children are sick and no one from the family comes to preschool for some time.

Another example of remote access to information concerns the handling of contact information. Keeping the contact information of all families up to date and available is a challenge. One of the reasons that the trials with manual email reminders about the early closing did not continue was that it was too cumbersome to collect email addresses to all parents and to keep the list up to date. We have also described above that it took so much time for teachers to help parents find phone numbers for each other that they finally posted a list on the wall so that parents could find the numbers themselves. An electronic record of contact information to which parents could get secure remote access and update their own information would be of great help and alleviate the teachers.

\subsection{Deviations from Routines}

When deviations from routines occur, which can happen frequently, extra support such as reminders is needed. The current practice includes written information in advance about the early closing, paper note on the front door the day previous to and the day of the closing, and oral reminders in the morning. However, as we described above, it is not always the person that gets reminded in the morning that will pick the child up early in the afternoon. Moreover, when deviating from an established routine, a reminder that occurs six or seven hours before the actual event might easily be forgotten. Situations like this could benefit from contextual reminders [5-7] through for example text messages to cell phones or email. A reminder to the right parent an hour or two before the child needs to be picked up would probably reduce the number of late pick-ups significantly. It would also relieve the teachers from awkward phone calls to remind parents that are running late. We also believe that especially text messages to cell phones would be well received by parents. For example two of our participants, P3 and P4, described how they already use their cell phones to remind them about important events. However, it is important that reminders can be set in advance and sent automatically since teachers do not have time to administer them in the afternoon.

\subsection{Discrepancies in IT Use}

It was obvious from the interviews that there is a discrepancy between how information technology is used in the preschool and how the interviewed parents used it in other parts of their lives. Information technology has only to a small extent entered the preschool while the parents were frequent users of email and the Web.

“For me I think maybe email would work better." (P1) 
When the parents communicated with each other, for example about organizing activities, they often used email. For example, when the parents organized a day of fixing things in the preschool and cleaning the yard, the vote about which day to do it was made by email. When the date was set, a paper note was distributed to everyone since that is the official way to announce an event. P2 also reported that the minutes from the last meeting with teachers and parents were taken by a parent and then emailed to everyone.

We believe that information technology could help to improve the information exchange between parents and preschool teachers in several ways. As described above, it can be used to provide remote access to information, to create contextual reminders, and allow parents to update their own contact information. We also believe that it can help by already being an integrated part of our participants existing organization systems. They reported in the interviews that they use email and the Web daily for both work and private purposes. In this respect we believe that our participants are representative for the Swedish population in general, for example did more than $85 \%$ of Swedes aged 16-45 use the Internet daily in 2008 [4]. Tapping into this existing behavior to disseminate preschool information therefore has good opportunities to work.

Privacy and the careful handling of personal information is an important issue here. Preschool have strict guidelines on how they are allowed to store and handle personal information which are often based on the paper based procedures but still need to be respected when moving to information technology. We envisage written consent and at least password protection for contact information on the Web. Our experience so far does not support the need for keeping other personal information such as the children's progress and development on the Web.

We are also aware of the current low use of information technology in preschool. Many teachers have little experience and little education, and the equipment is often old. Extreme care need to be taken when introducing new technology and new use of the existing technology as to not burden teachers. We are trying to improve the information exchange to give teachers more time with the children. It is therefore crucial that the proposed solution does not eat up the liberated time.

\section{Future Work}

Based on the findings presented here we are continuing to work with teachers and parents at this preschool and five others in the Stockholm area to create information tools that fulfill the needs we have identified. We are planning a web interface for teachers to create simple web pages for the child groups that are accessible from computers and cell phones. That way, parents get remote access to information. The system will also support automatic email reminders in the first step, and automatic text message reminders to cell phones in the second step. To inform the design of this system further we plan to interview more parents and teachers from the different preschools in addition to the interviews presented here.

\section{Conclusions}

Based on interviews with parents and a preschool teacher, we have identified presence and routines as important foundations for the information exchange between parents 
and preschool teachers. Parents come to preschool daily and pick up paper notes, talk to teachers, and look at notice boards. They also often have schedules on who is dropping of and picking up the children on different days of the week. In the interviews we found that in case of absence from preschool, for example due to illness or travel, and when deviations from routines occur, there are often breakdowns in the parentteacher information exchange. This has led us to consider ways of making the information remotely accessible, and provide reminders in situations that deviate from routines. Web access to some of the information from preschool would make it possible to check what is coming up for example from work or other places. We also believe that an increased use of information technology from the part of the teachers, to match that of the parents, would improve the information exchange.

Acknowledgements. We would like to thank the parents and preschool teachers that took time from their busy schedule to talk to us. Thanks also to Squace AB that supported this pilot study and will be a partner in future work in this area. This work has been funded by the Swedish Governmental Agency for Innovation (Vinnova).

\section{References}

1. Crabtree, A., Hemmings, T., et al.: Informing the Development of Calendar Systems for Domestic Use. In: Proceedings of ECSCW, pp. 119-138 (2003)

2. Davidoff, S., Lee, M.K., Yiu, C., Zimmerman, J., Dey, A.K.: Principles of smart home control. In: Dourish, P., Friday, A. (eds.) UbiComp 2006. LNCS, vol. 4206, pp. 19-34. Springer, Heidelberg (2006)

3. Elliot, K., Neustaedter, C., Greenberg, S.: Time, ownership and awareness: The value of contextual locations in the home. In: Beigl, M., Intille, S.S., Rekimoto, J., Tokuda, H. (eds.) UbiComp 2005. LNCS, vol. 3660, pp. 251-268. Springer, Heidelberg (2005)

4. Findahl, O.: Svenskarna och Internet 2008 (In Swedish. The Swedish people and the Internet 2008), World Internet Institute (2008)

5. Lee, M.K., Davidoff, S., et al.: Smart Bag: Managing Home and Raising Children. In: Proceedings of Designing Pleasurable Products and Interfaces, Helsinki, Finland, pp. 434-437 (2007)

6. Ludford, P.J., Frankowski, D., et al.: Because I Carry My Cell Phone Anyway: Functional Location-Based Reminder Applications. In: Proceedings of CHI 2006, Montréal, Canada, pp. 889-898. ACM Press, New York (2006)

7. Neustaedter, C., Bernheim Brush, A.J.: "LINC-ing" the Family: The Participatory Design of an Inkable Family Calendar. In: Proceedings of CHI, Montréal, Quebec, pp. 141-150. ACM Press, New York (2006)

8. Neustaedter, C., Bernheim Brush, A.J., et al.: A Digital Family Calendar in the Home: Lessons from Field Trials of LINC. In: Proceedings of Graphics Interface Conference, Montréal, Canada, pp. 199-206 (2007)

9. Nylander, S.: Presence as a Foundation for Information Exchange between Parents and PreSchool Teachers. In: Proceedings of CSCW Extended proceedings, San Diego, CA (2008)

10. Taylor, A.S., Swan, L.: Artful Systems in the Home. In: Proceedings of CHI, Portland, Oregon, pp. 641-650. ACM Press, New York (2005)

11. Taylor, A.S., Swan, L.: List Making in the Home. In: Proceedings of CSCW, Chicago, Illinois, pp. 542-545 (2004)

12. Tolmie, P., Pycock, J., et al.: Unremarkable Computing. In: Proceedings of CHI, Minneapolis, Minnesota, pp. 399-406. ACM Press, New York (2002) 